Yves Gambier (Turku)

\title{
Multimodality and Audiovisual Translation
}

\section{Contents}

$\begin{array}{ll}1 & \text { Introduction } \\ 2 & \text { Piecemeal research } \\ 3 & \text { TS and AVT } \\ 4 & \text { The challenge of accessibility and reception } \\ 5 & \text { The socio-cultural relevance of applied research } \\ 6 & \text { The contribution of multimodality in the study of subtitling } \\ 7 & \text { To conclude } \\ 8 & \text { References }\end{array}$

\begin{abstract}
The current development of audiovisual translation (AVT) is fragmented. However, several challenges must be taken up if we want to better understand the impact and consequences of AVT on our daily habits. Therefore, this paper raises four main issues: the need to revise and rethink certain concepts in Translation Studies, because of digitisation; the urgent need to carry out reception studies in order to provide AV programmes accessible to all; the need to highlight the sociocultural relevance of applied research, in such a way that the field is not any longer considered as a constellation of problems but a valuable asset addressing the demand for multilingual and multicultural communication; and finally, the need to find out a methodology able to deal with multimodality - otherwise the major risk is to focus on language, precluding from comprehending these challenges.
\end{abstract}

\section{Introduction}

In the digital era, some people cannot avoid trying to catch a magic glimpse of the future of film: with digitization, it would be far cheaper to shoot, cut, edit, duplicate, distribute, and release films, and even cheaper to write scripts, produce special effects, adjust the lights, dress the set, apply the makeup, find the costume and provide screen translation. For others, the brave new digital world does not help you to tell a better story, will not replace the mystical experience of watching a film in a cinema.

However, for everybody - including the translator - the length of time between films being made and when they are shown (in DVD, on the Internet and the mobile phone) is getting shorter, the commercial and technical convergence between the media, telecommunication and Information and Communication Technology (ICT) is speeding up, and the relationship between the copyright holders and broadcasters is also changing rapidly.

For these reasons, we could dream of digitopia. But here, my intention is not to deal with the implications of technology. Let me only mention that new services such as streaming, video and TV on demand, TV on mobile (with new types of very short films), podcasting, etc., will challenge not only providers but also screen translators. The way we will access and consume audio-video-radio programs will change the whole management and financing of the audiovisual (AV) sector. I also believe the type and size of the programs will give new impetus to dubbing, interpreting and voice-over. That is enough for the technical background of my presentation. 
I would like to raise five issues:

- The current development of audiovisual translation (AVT) research; Where are we aiming at?

- The need to revise a certain number of concepts in Translation Studies (TS), thanks to AVT

- The challenge of accessibility and reception

- The sociocultural relevance of applied research; AVT should not be seen as a constellation of problems but as a valuable asset addressing the need for multilingual and multicultural communication in the international arena

- The contribution of multimodality in the study of AVT, especially in subtitling

\section{Piecemeal research}

Over the last decade, a few systematic studies have examined the production and reception or the cultural and linguistic impact of AVT.

AVT has benefited from the rapid development of research interest and of institutional commitment, especially intralingual subtitling for the deaf and hard of hearing, but the discipline remains essentially European, and too often limited to case studies on the linguistic side only, where no sides are taken in the long-running debate on the respective merits of subtitling or dubbing.

However, the field has gained gradual recognition, but it has not yet definitely established its place, either within TS or in relation to other disciplines such as semiotics, media studies, and discourse/pragmatic studies. That may be why AVT is not yet seen as one solution to internationalization, situating it within the context of power-related, cultural and linguistic issues in today's societies. More often than not, our studies are limited to professional routines, the production process and quality of the output, while too seldom do they emphasize the decision-making (Why, for instance, are advertisements very often dubbed, even in a so-called subtitling country? Who defines the translation policy in TV broadcasting companies and, in particular, who allocates money for translating? etc).

Our field remains too much on the level of isolated descriptions, incurring the risk of fragmentation, and claiming neutrality through a kind of informative mode of discourse: Catalans tell us about Catalan TV, Danes about Danish TV, Germans about subtitling for the deaf and the hard of hearing-impaired in Germany, Portuguese about the same mode for the same group of people, and so on, as if mediascape were not global, formats were not more and more international, outsourcing and relocation did not exist, there were no multinational networks unrestrained by national legislation. Can AVT be considered a positive solution in a world which is increasingly dependent on multimodal and multimedia products and services? In the current media scenario, there is an ongoing transfer of power - from the media owners to the distributors and professionals who manipulate (literally speaking) the multiple codes. Translators are part of this new group but do not yet realize what this implies or recognize its full effects. Our field remains fragmented, with a vision limited to certain aspects and shortterm goals (Gambier 2005). My point here is to emphasize the fragmentation of our research, basically for one reason: our relative specialization. We tend to be specialist technicians even among ourselves: subtitlers are not dubbers, interpreters do not practise voice-over, and so on, and so forth. Furthermore, no one seems to approach the people who decide translation policies. 


\section{TS and AVT}

Certain concepts in TS should arguably be revised, extended and rethought when they are applied to AVT. I will not give here an exhaustive list but mention only a few concepts.

- The notion of text: screen texts are short-lived and do not fit readily into the traditional dichotomy between source text and target text. They are also distinctive in that they are multimodal. But is this not true of any text? Tourist brochures, press articles, art books, children's books, instruction leaflets, exhibition catalogs, illustrated books and advertisements all combine writing and illustrations (photos, drawings), with considerable scope for variety in the way printing, punctuation and the arrangement of space on the page are used. Is it appropriate, then, to continue speaking of verbal units? Does text mean the same thing in literary translation, conference interpreting and AVT? The traditional concept of linear and verbal text cannot account for the full range of multi-semiotic textual phenomena. And I do not mention here hypertext, defined as a concept and a new means for structuring and accessing documents in distance communication, with interconnection by means of electronic links. There might be more convergence between screen texts and multimedia texts than between screen texts and traditional texts. Anyway, the constitutive criteria of textuality could be developed and adapted to screen texts, criteria such as coherence, situationality, informativity, and intertextuality.

- AVT researchers also have to think critically about the concept of sense, since this is produced neither in a linear sequence nor with a single system of signs. There is interaction not only between the various figures involved in creating the AV product, but also between them and the viewers - even between different AV productions (references, allusions). The hierarchy of original and subsequent distribution or broadcasting becomes questionable, given that intellectual property rights on a film often offer various versions (one for TV, one for use as an airline feature film, or yet another version in which offensive language has been censored in compliance with the demands of political correctness). Digital technology also allows different users (parents, educators, religious associations, ideological groups, etc.) to have access to their own personalized final cut. And what about the concept of loss so often mentioned when referring to AVT? It cannot be restricted to verbal elements. Is there not a certain loss in the meaning of pictures when one reads subtitles? Can we not talk about language hypertrophy, paying less attention to camera moves, viewing angles, editing, soundtrack, tone of voices, facial expressions, gestures, gazes, body movements, all of which are also meaningful?

- The issue of text and sense entail questions regarding translation units in AVT. These units can be based on the predictability of language use and occurrences, themselves related to scene types, as defined and described in cognitive semantics and when you learn how to write scripts.

- The very concept of translation highlights a lack of consensus, overlapping as it does those of adaptation, manipulation, censorship, transfer and remake.

- It is important to reconsider the links between translation norms, which originate and are passed on against a social background, and technical constraints (Fawcett 1996, 2003). In this respect, it is already possible to speak of "abusive" subtitles, for example, those accompanying Japanese animated cartoons on the Internet, produced by amateurs who ignore accepted subtitling conventions and introduce typographic variations, adding glosses or commentaries or changing the position of lines (Norns 1999, Sinha 2004). We already know that films are less and less often seen in cinemas 
and more and more released in DVD form and on the Internet. Therefore changes in norms are to be expected.

- Another relevant issue is the relationship between written and oral, between norms for written texts and the written language of subtitles, between ordinary speech and dubbese. In a broader perspective, this leads on to the long-term effects of written communication based on symbols and abbreviations, as in SMS messages and on-line chats or conversations. Not so long ago, suggesting subtitles with emoticons, pictograms and abbreviations might well have seemed provocative. Changing attitudes to spelling are reflected, for example, in the city of Montreal's Internet site, which can be accessed in three different ways (www.ville.montreal.qc.ca $\rightarrow$ click on "accès simple"), including what is called the "ortograf altêrnativ", matching letters (graphemes) and sounds (phonemes) to facilitate access for "people with intellectual incapacities" ( $\mathrm{sic}$ ). Examples of such spelling in French are "dan bokou de kartié", "lê list dê z'aktivité é dê servis son fêt for le sitouayin" or "alé vouar". "Simplicity" of this kind is distinct from a simplified version of the text's content, which is also available. This provides, by the way, an argument for viewing the output of machine translation programs (whether commercialized or shareware) in a different light, in that they satisfy a certain number of users who are far from illiterate but who do not need a polished, finely honed text.

- Finally, reception of AV products is a notion on which there is nothing like consensus, since this broad notion might include the $3 \mathrm{Rs}$, namely reactions on the cognitive level, responses in behavioral terms, and repercussions of a cultural order (Kovačič 1995, Chesterman 2005).

\section{The challenge of accessibility and reception}

Accessibility has for a number of years been a legal and technical issue in various countries, with a view to ensuring that handicapped persons can enjoy physical access to transport, facilities and cultural venues (ramps, inclined surfaces, parking, low-floor buses, etc.). Recently, accessibility has also become an important issue in the computer and telecommunications industries, the aim being to optimize the user-friendliness of software, web sites and other applications. Distribution of AV media is also involved in this trend, since it is important to cater for the needs of user groups such as the deaf. The issue of accessibility is, however, not merely a question of providing for special visual, auditory, motor or cognitive needs; such a view of the issue is far too restrictive in the light of the digital divide, income-related differences in Internet use, and the exclusion of certain sectors of society from access to information. Accessibility means that AV or electronic products and services must be available to all users, irrespective of issues such as where they live, their level of experience, their physical and mental capacity, or the configuration of their computer. Accessibility is not just an issue for the disabled: it does not only mean a barrier-free situation; it also means that services are available and that information is provided and easy to understand.

In my opinion, there is a strong relationship between usability as a measure of the effectiveness, efficiency and satisfaction with which specified users can achieve specified goals in a particular environment (as a web site or a software or an AV product) and accessibility as a means to make web content, and film content available to all users, whatever tool they are using (voice browser, mobile phone, etc.) or whatever constraints they may be operating under (noisy surrounding, under-illuminated room, etc.) The goal of usability is a better experience for the user; the goal of accessibility is equality of access - both have implications for design and the use of different semiotic systems as color, font size, 
punctuation, intonation, voice pitch, and so on. Both can help us to better understand the effects of screen translation, and to better understand the convergence between AVT and multimedia translation.

What we need now is to discern the needs of different users, to know the viewers' needs and reception capacity, whatever the modality of AVT being offered: media interpreting, live subtitles (respeaking), audio description, etc. While relatively little academic research has been done (often unpublished), some of the slack has been taken up by other forms of research, e.g. commercial and advertising studies based on Audimat, marketing surveys among distributors, feasibility studies involving electronics and telephone companies. User reactions, demands and expectations are thus not totally unknown.

However, how can producers and screen translators make the most informed decision when there is so little reliable and available research? Audio description for the blind, voiceover for experts or for children watching documentaries could be adapted for different subgroups if we had a better knowledge of their capacities, habits and technological literacy. The challenge goes far beyond the usual discussions among translators, more concerned with problems of linguistic transfer than with the wider effects and functions of their work. Directly or not, clearly or not, the context of reception of an AV product and its genre affect the decisions made by translators. In all cases, the translator selects different strategies and assumes a certain knowledge and cognitive frames in the viewers. Effectiveness, in term of pragmatics, means that the greater the viewers' processing effort, the lower is the relevance of the translation.

Reception studies can use different methods of investigation (de Linde \& Kay 1999), according to the level of reception (cf. section 2, the three Rs: reactions, responses and repercussions):

- Survey methods, eliciting viewers' responses with questionnaires, interviews

- Experimental methods, providing insights into the effects of particular translation features

- And controlled procedures, designed to record actual motor behavior, for instance to study the different forms of attention (active/passive/selective/global/linear). Here we could use eye-movement monitors/cameras and eye-tracking methodology, already used in studies on reading web sites

\section{The socio-cultural relevance of applied research}

One of the fundamental convictions in my presentation is that AVT should be seen not as a constellation of problems but as a valuable asset addressing the need for multilingual and multicultural communication.

In Finland today, the two public television channels broadcast over 2 millions subtitles per year (2003). The amount of text equals roughly 120 novels of 300 pages each.

The European Barometer carried out an opinion poll in November-December 2005. The survey shows clearly that using subtitles can encourage and facilitate language learning. But, on average, only $10 \%$ of European Union (EU) citizens state that they have used watching films in their original version as a way to learn languages. However, the majority of Europeans (56\%) would rather watch foreign films and programs dubbed than hear the original language with subtitles. These figures are not given here to restart the long-running debate subtitling vs. dubbing, but to emphasize the need for more evidence on the use and usefulness of the different modalities of AVT.

The AV media certainly play a major linguistic role today, especially in private homes, just as school and literature did in the past. However, what has been focused on to date has 
been mostly the indirect didactic role played by such media. Looking at subtitled programs, it is as if one were reading the television. But there is still no research on the possible correlation between viewing or reading of subtitles and the absence of illiteracy in a given society. Channels like TV5, BBC4 and TV4 nevertheless offer their audiences (intralingual) subtitles, irrespective of the degree of mastery of the language concerned.

Again my concern here is to focus on the social or rather socio-cultural function of translation.

Certainly, if we could demonstrate that programs and films with interlingual or intralingual subtitles help viewers not only to maintain or even reinforce their ability to read but also to learn foreign languages (assimilating foreign sounds, expressions or accents), I am sure certain TV broadcasters and film distributors would pay more attention to subtitling and the working conditions of the subtitlers. The same applies if we could prove the possible role of subtitles in language acquisition by the deaf and hard of hearing. In other words, what are our priorities in our agenda? Will we go on studying the translation of humor while the EU Commission would like to know if subtitling should be promoted as a learning tool?

Another field of applied research is quality, an issue which has been widely debated in recent years in translation generally but which has not yet prompted too much research in AVT (Gambier 1999). Quality goes hand in hand with reciprocal cooperation and trust between service providers and their clients. It is the result of a collective and joint effort, although many translators think that they hold the monopoly on quality. Producers, distributors and viewers are also involved, their expectations and demands not necessarily coinciding with the translators' since they do not always stem from language considerations, nor are they based on the written language of the subtitlers. The social implications of this are important: between the producer or screen writer who does not give a single thought to translated dialogues and the young SMS or chat enthusiast, the translator will not always have the last word - particularly if s/he fails to explain the role s/he should play in cultural mediation and in the development of subtitle users' reading and language learning skills.

Quality is thus defined by both external parameters (linked to viewers' needs and expectations) and intrinsic criteria (linked to such factors as translators' skills, labor organization, and the specific features of the AVT modality). Localization has quality assurance thanks to LISA (Localization Industry Standards Association), the automobile industry has its SAE J2450 quality norms, but the work done to ensure legibility, information content and precision in subtitling has still not led to an accepted code of best practice for AVT.

I have mentioned above (section 2) the challenge of the norm for written texts and the written language of subtitles. What will be the decision of the translator if a commercial TV broadcasting company requires him or her to use smileys, abbreviations, pictograms while, at the same time, a public channel requires a very standardized written subtitling? The answer cannot be given only from a financial perspective (the translator needs money every day); there is here an ethical challenge, based on the role and function of the translator. Many video games are based on films (e.g. Harry Potter, Star Wars III, Spiderman, King Kong) and many films nowadays are based on video games (e.g. Silent Hill). To what extent does the same translator have to adapt not only different strategies but also different behaviors?

\section{The contribution of multimodality in the study of subtitling}

No text is, strictly speaking, monomodal. Traditional texts, hypertexts, screen texts combine different semiotic resources. Films and TV programs co-deploy gesture, gaze, movement, visual images, sound, colors, proxemics, oral and written language, and so on. Although many kinds of texts with different types of signs are dealt with in Translation Studies (AV, 
advertising, theatre, songs, comics), the focus tends to be limited to their linguistic features. There is a strong paradox: we are ready to acknowledge the interrelations between the verbal and the visual, between language and non-verbal, but the dominant research perspective remains largely linguistic. The multisemiotic blends of many different signs are not ignored but they are usually neglected or not integrated into a framework. Is it not a contradiction to set up a data base or a corpus of film dialogues and their subtitles, with no pictures, and still pretend to study screen translation?

Two factors probably explain this paradox: on the one hand, the linguistic and literary background of most of the researchers; on the other hand, the practical constraints of data collection and annotation (time-consuming and copyright problems), and (printed) publication (in two dimensions). The potential of CD, DVD, and Internet-based technology should gradually change these trends.

A third factor must be added: the lack, until recently, of a relevant methodology to deal with multimodality. I believe, however, that the multimodal discourse analysis will help to develop awareness and analysis of the integration of semiotic resources in AV, such as films, and multimedia products, such as web pages.

This is not the place to lecture about the multimodal transcription technique (Baldry \& Taylor 2002; Taylor 2003, 2004) and how it provides an analysis of a video clip, for instance, by breaking it down into individual frames, and how it allows you to identify recurrent patterns in the clip. Multimodal text analysis assumes that the meaning of a film, a TV ad, a web page, a cartoon, a comic book, is the composite process/product of different selected semiotic resources (Baldry \& Thibault 2006). Such an analysis which can be long (more than 30 pages for 60 seconds of a TV ad) is very useful for trainee subtitlers, for scholars, but not for professionals (ibid.: 46-51, 165-251). It sheds light on our perception and processing of various AVT modalities: for instance, do images account for less than $50 \%$ in the meaningmaking in a dubbed version? For more than $50 \%$ in the subtitled version? Do the viewers base their interpretation more on the verbal text in the beginning of a film?

Another way to understand multimodality is, in my opinion, through script writing. Screenwriting represents a form of story telling that presents three classes of features (Cattrysse \& Gambier forthcoming). Some of these features are common to story-telling in general (for example, oral narration, drama, film etc), irrespective of the medium that is used. A second set of features is typical of drama writing (with a plot, a conflict, a climax, and with characters). The third category includes atmosphere (sound, setting and costumes), camera positions, editing and post-production operations. Knowing these characteristics, and how they are combined may enhance the translation process and increase the skill of the translator. If you know how to visualize love at first sight, the tension between two relatives, you will learn the value of the words.

\section{To conclude}

According to Eurodata TV Worldwide, television was watched in 2005, in 64 countries, for 3 hours and 4 minutes a day, 28 minutes longer than in 1995. With the new digital technology, this average can only increase (with, in passing, the problem of definition of an AV work which is not only a legal or semantic matter because it has financial implications). In this changing mediascape, the translators have and will have a major role, if they fully realize their socio-cultural function. 


\section{References}

Baldry, Anthony \& Taylor, Chris (2002): 'Multimodal Corpus Authoring System: multimodal corpora, subtitling and phasal analysis'. In Maybury, Mark \& Martin, Jean-Claude (eds): Multimodal Resources and Multimodal Systems Evaluation. Las Palmas: LREC Congress, Post-conference Workshop Papers. 45-51.

Baldry, Anthony \& Thibault, Paul J. (2006): Multimodal Transcription and Text Analysis. A multimedia toolkit and coursebook. London \& Oakville: Equinox.

Cattrysse, Patrick \& Gambier, Yves (forthcoming): 'Screening and translating screenplays'. In Diaz-Cintas, Jorge (ed.): The didactics of Audiovisual Translation. Amsterdam \& Philadelphia: John Benjamins.

Chesterman, Andrew (2007): 'Bridge Concepts in Translation Studies'. In Wolf, Michaela \& Fukari, Alexandra (eds): Translation Sociology. A new discipline under construction. Selected papers from the International conference on Translating and Interpreting as a Social Practice, Graz, 5-7 May 2005. Amsterdam \& Philadephia: John Benjamins.

Linde, Zoe de \& Kay, Neil (1999): The Semiotics of Subtitling. Manchester: St Jerome.

Fawcett, Peter (1996): 'Translating films'. In Harris, Geoffrey T. (ed.): On Translating French Literature and Film. Amsterdam: Rodopi. 65-88.

---- (2003): 'The manipulation of language and culture in film translation'. In Pérez, Calzada (ed.): A propos of Ideology. Translation Studies and Ideology, Ideologies in Translation Studies. Manchester: St Jerome. 145-163.

Gambier, Yves (1999): 'Qualités dans le sous-titrage. Paramètres et implications'. In Traduction, Transition, Translation. Proceedings of the XVth World FIT Congress, Mons, August 1999, vol.1. 151-157.

---- (2006): 'Orientations de la recherche en traduction audiovisuelle'. In Target 18 (2). 261293.

Gambier, Yves (forthcoming): 'Recent developments and challenges in Audiovisual Translation'. In Chiaro, Delia \& Heiss, Christine \& Bucaria, Chiara (eds): Between Text and Images. Conference Proceedings, Forlì, 27-29 October 2005. Amsterdam \& Philadelphia: John Benjamins.

Kovačič, Irena (1995): 'Reception of subtitles. The non-existent ideal viewer'. In Translatio (FIT Newsletter) 14 (3-4). 376-383.

Norns, A.M. (1999): 'For an abusive subtitling'. In Film Quarterly 52 (3). 17-33.

Sinha, Amresh (2004): 'The use and abuse of subtitles'. In Egoyan, Atom \& Balfour, Ian (eds): On the foreignness of film. Massachussetts \& Toronto: The MTI Press \& Alphabet City Media. 171-192.

Taylor, Christopher (2003): 'Multimodal Transcription in the Analyis, Translation and Subtitling of Italian Films'. In The Translator 9(2). 191-205.

---- (2004): 'Multimodal Text Analysis and Subtitling'. In Ventola, Eija \& Cassily, Charles \& Kaltenbacher, Martin (eds): Perspectives on Multimodality. Amsterdam \& Philadelphia: John Benjamins. 153-172. 